\title{
Precision of the transpulmonary thermodilution measurements
}

\author{
Xavier Monnet ${ }^{1,2^{*}}$, Romain Persichini ${ }^{1,2}$, Mariem Ktari ${ }^{1,2}$, Mathieu Jozwiak ${ }^{1,2}$, Christian Richard ${ }^{1,2}$ and \\ Jean-Louis Teboul ${ }^{1,2}$
}

\begin{abstract}
Introduction: We wanted to determine the number of cold bolus injections that are necessary for achieving an acceptable level of precision for measuring cardiac index (CI), indexed global end-diastolic volume (GEDVi) and indexed extravascular lung water (EVLWi) by transpulmonary thermodilution.

Methods: We included 91 hemodynamically stable patients (age 59 (25\% to 75\% interquartile range: 39 to 79 ) years, simplified acute physiologic score (SAPS)|I 59 (53 to 65), 56\% under norepinephrine) who were monitored by a PiCCO2 device. We performed five successive cold saline $\left(15 \mathrm{~mL}, 6^{\circ} \mathrm{C}\right)$ injections and recorded the measurements of $\mathrm{Cl}, \mathrm{GEDV}$ i and EVLWi.

Results: Considering five boluses, the coefficient of variation ( $\mathrm{CV}$, calculated as standard deviation divided by the mean of the five measurements) was 7 (5 to 11)\%, 7 (5 to 12)\% and 7 (6 to 12)\% for Cl, GEDVi and EVLWi, respectively. If the results of two bolus injections were averaged, the precision $(2 \times \mathrm{CV} / \sqrt{ }$ number of boluses $)$ was 10 (7 to 15)\%, 10 (7 to 17)\% and 8 (7 to 14)\% for Cl, GEDVi and EVLWi, respectively. If the results of three bolus injections were averaged, the precision dropped below $10 \%$, that is, the cut-off that is generally considered as acceptable (8 (6 to 12)\%, 8 (6 to 14)\% and 8 (7 to 14)\% for Cl, GEDVi and EVLWi, respectively). If two injections were performed, the least significant change, that is, the minimal change in value that could be trusted to be significant, was 14 (10 to 21)\%, 14 (10 to 24)\% and 14 (11 to 23)\% for Cl, GEDVi and EVLWi, respectively. If three injections were performed, the least significant change was 12 (8 to 17)\%, 12 (8 to 19)\% and 12 (9 to 19)\% for Cl, GEDVi and EVLWi, respectively, that is, below the 15\% cut-off that is usually considered as clinically relevant.
\end{abstract}

Conclusions: These results support the injection of at least three cold boluses for obtaining an acceptable precision when transpulmonary thermodilution is used for measuring Cl, GEDVi and EVLWi.

\section{Introduction}

Transpulmonary thermodilution (TPTD) is increasingly used in the clinical area [1], but its precision for measuring $\mathrm{CI}$ and the number of cold boluses that must be replicated is a matter of debate. Indeed, a recent study concluded that calculating the mean of two TPTD measurements was enough for reaching an acceptable level of precision [2] but it included a limited number of patients. Additionally, for another transpulmonary dilution technique using the lithium and not the cold dilution, it has been recently shown that at least three dilution measurements were required for reaching an

\footnotetext{
* Correspondence: xavier.monnet@bct.aphp.fr

${ }^{1}$ AP-HP, Hôpitaux Universitaires Paris-Sud, service de réanimation médicale, Le Kremlin-Bicêtre, F-94270 France

Full list of author information is available at the end of the article
}

acceptable precision. In addition to CI, TPTD also allows estimating the global end-diastolic volume (GEDV, that is, the volume of the cardiac cavities at end-diastole) and the extravascular lung water (EVLW, that is, the volume of the pulmonary edema) [3]. The precision of EVLW measurement derived from TPTD has been reported by some studies [2,4-6], but again, the number of cold injectates that is needed for obtaining an acceptable reproducibility of the measurements remains to be determined. As for GEDV, its precision has been investigated in one study only [2].

Thus, we attempted to answer the important practical question to know the number of thermal injections that must be performed for assessing CI, GEDV and EVLW with an acceptable precision. In particular, we evaluated the number of thermodilution measurements that must

\section{Biomed Central}


be replicated for detecting changes in CI, GEDV and EVLW $\geq 15 \%$ with an acceptable confidence. We also analyzed the factors influencing the precision of the measurements.

\section{Materials and methods Patients}

This prospective study was conducted in the 15-bed intensive care unit of a university hospital. As approved by the Institutional Review Board of our institution, patients were included according to an emergency procedure. A deferred informed consent was asked from the patient's surrogate as soon as possible. As he/she recovered consciousness, a deferred informed consent was asked from the patient. If the patient or his/her next of kin refused to consent, the patient's data were not entered into analysis.

Patients were included if they had a femoral arterial catheter (Pulsiocath PV2015L20N, Pulsion Medical Systems, Munich, Germany) and an internal jugular catheter in place and were routinely monitored by a $\mathrm{PiCCO} 2$ device (Pulsion Medical Systems, Munich, Germany). Patients were excluded if they were less than 18 years old and if haemodynamic instability did not allow the mean arterial pressure to remain stable (changes by more than $10 \%$ ) during at least five minutes before starting the study. Patients with cardiac arrhythmias were not excluded. No patient had a pacemaker.

\section{Study design and measurements}

Immediately after inclusion, one of the investigators (RP) injected five successive cold boluses, each according to the manufacturer's recommendation [7]. For each bolus, we injected $15 \mathrm{~mL} 0.9 \%$ saline at $6^{\circ} \mathrm{C}$ through the distal port of the internal jugular catheter. The injection was performed as rapidly as possible, irrespective of the respiratory cycle. The injectate temperature was carefully checked to be $<6^{\circ} \mathrm{C}$ for all boluses, as displayed by the PiCCO device. For ensuring that boluses were $<6^{\circ} \mathrm{C}$, we used two packs of saline, one frozen and one at $6^{\circ} \mathrm{C}$. For each bolus, we sampled $20 \mathrm{~mL}$ from the $6^{\circ} \mathrm{C}$ saline pack, injected it into the iced pack and re-sampled 15 $\mathrm{mL}$ from this saline that had been cooled by the contact with ice. These $15 \mathrm{~mL}$ were used for performing the bolus. The thermodilution curve recorded by the arterial thermistance was automatically analyzed by the $\mathrm{PiCCO} 2$ device, allowing obtaining the value of cardiac output, of GEDV indexed for body surface (GEDVi) and of EVLW indexed for predicted body weight (EVLWi). The five boluses were performed one after another, as soon as blood temperature had returned to its baseline value, as indicated by the device. The values of CI, GEDVi and EVLWi obtained from each thermodilution were collected. No thermodilution curve was rejected from analysis. Treatments were kept unchanged and patients were not mobilized during the study period. All measurements were performed by the same operator (RP).

\section{Data analysis}

In each patient, we calculated the coefficient of variation (CV) of the TPTD variables (CI, GEDVi and EVLWi). The CV is a normalized measure of dispersion of a probability distribution. It was calculated as being the standard deviation divided by the mean of the five measurements. This relatively large number of measurements thus allowed obtaining a reliable value of $\mathrm{CV}$. The coefficient of error (CE) was obtained by using the formula $C E=C V / \sqrt{ }$, were $n$ was the number of replicates of measurements in each patient. The precision was calculated as being two $\mathrm{CV}$ for a single measurement and two CE for averaged measurements. It is usually considered that a measurement precision level $\leq 10 \%$ is desirable [8]. The least significant change (LSC) is the minimum change that needs to be measured by a device in order to recognize a real change of measurement [9]. The LSC was calculated using the following equation: $\mathrm{LSC}=\mathrm{CE} \times 1.96 \times \sqrt{ } 2$.

All data except CE, precision, LSC and the dose of norepinephrine were normally distributed (KolmogorovSmirnov test for normality) and were expressed as median (25 to $75 \%$ interquartile range). As we initially planned to divide our population into five different subgroups depending upon the value of $\mathrm{CI}$, we planned to include a sufficient number of patients (100) for reaching a normal distribution of $C I$ in all subgroups. A $P$ value $<0.05$ was considered statistically significant. The statistical analysis was performed with MedCalc 8.1.0.0 (Mariakerke, Belgium).

\section{Results}

\section{Patients' characteristics}

A hundred different patients were initially included in the study. Their characteristics are detailed in Table 1 . In nine patients, the TPTD could not measure any variable, likely due to low CI, as suggested by the values observed during the preceding hours. The PiCCO device was instituted due to septic shock in $80 \%$ of patients in all patients and it was in place since 28 (5 to 50) hours. Atrial fibrillation was observed in $20 \%$ of patients (Table 1). Eighty-three percent of patients were under mechanical ventilation and $74 \%$ were sedated. A spontaneous breathing activity was observed in 23 (26\%) patients. Eight patients were under continuous veno-venous hemofiltration for renal replacement therapy. The dialysis catheter was inserted in the jugular vein and the blood pump flow was $300 \mathrm{~mL} /$ minute. 
Table 1 Patients characteristics at baseline

\begin{tabular}{|c|c|}
\hline Age (years, median ( $25 \%$ to $75 \%$ IQR)) & 59 (39 to 79$)$ \\
\hline Gender (M/F) & $65 / 26$ \\
\hline SAPS II (median ( $25 \%$ to $75 \%$ IQR)) & $59(53$ to 65$)$ \\
\hline Height (cm, median ( $25 \%$ to $75 \%$ IQR)) & 175 (170 to 180$)$ \\
\hline Weight (kg, median (25\% to $75 \%$ IQR)) & 80 (68 to 92$)$ \\
\hline \multicolumn{2}{|l|}{ Cause of shock } \\
\hline septic (n, \%) & $73(80)$ \\
\hline cardiogenic (n, \%) & $10(11)$ \\
\hline hypovolemic (n, \%) & $8(9)$ \\
\hline \multicolumn{2}{|l|}{ Catecholamines } \\
\hline norepinephrine $(\mathrm{n}, \%)$ & $51(56)$ \\
\hline dobutamine (n, \%) & $7(8)$ \\
\hline Heart rate (beats/minute, median ( $25 \%$ to $75 \%$ IQR)) & 86 (70 to 99$)$ \\
\hline $\begin{array}{l}\text { Mean arterial pressure ( } \mathrm{mmHg} \text {, median ( } 25 \% \text { to } \\
75 \% \text { IQR)) }\end{array}$ & 80 (72 to 90$)$ \\
\hline Body temperature $\left({ }^{\circ} \mathrm{C}\right.$, median $(25 \%$ to $75 \%$ IQR)) & 37.1 (36.4 to 37.5$)$ \\
\hline \multicolumn{2}{|l|}{ Cardiac rhythm } \\
\hline sinus rhythm (n, \%) & $72(79)$ \\
\hline atrial fibrillation (n, \%) & $18(20)$ \\
\hline frequent atrial extrasystoles (n, \%) & $1(1)$ \\
\hline $\begin{array}{l}\text { Cardiac index }\left(\mathrm{L} / \text { minute } / \mathrm{m}^{2}, \text { median }\right. \\
(25 \% \text { to } 75 \% \mathrm{IQR}))\end{array}$ & $3.5(2.7$ to 4.3$)$ \\
\hline EVLWi (mL/kg, median ( $25 \%$ to $75 \%$ IQR)) & 9 (8 to 14$)$ \\
\hline GEDVi (mL/m², median ( $25 \%$ to $75 \%$ IQR)) & 812 (705 to 932 ) \\
\hline
\end{tabular}

$\mathrm{N}=91$

Data are expressed as median ( $25 \%$ to $75 \%$ interquartile range (IQR)) or as $\mathrm{n}$ (\%).

SAPS, Simplified Acute Physiologic Score; EVLWi, extravascular lung water indexed for predicted body weight; GEDVi, global end-diastolic volume indexed for body surface.

\section{Precision of the TPTD measurements}

Considering five boluses, the average CI was 3.5 (2.7 to 4.3) $\mathrm{L} / \mathrm{minute} / \mathrm{m}^{2}$, the GEDVi was 812 (708 to 932$) \mathrm{mL} /$ $\mathrm{m}^{2}$ and the EVLWi was 9 ( 8 to 14$) \mathrm{mL} / \mathrm{kg}$ (Table 1 ). The precision for one single measurement was 14 (10 to 21 )\% for CI, 15 (10 to 24)\% for GEDVi and 15 (11 to $24) \%$ for EVLWi and the precision for CI was $\geq 10 \%$ in 66 patients. If two boluses were used for TPTD, the precision was reduced to 10 (7 to 15 )\% for CI, 10 (7 to 17)\% for GEDVi, 10 (8 to 17)\% for EVLWi (Figure 1) and the precision for CI was $\geq 10 \%$ in 47 patients. If three boluses were used for TPTD, the precision was reduced to 8 (6 to 12 )\% for $\mathrm{CI}, 8$ (6 to 14$) \%$ for GEDVi, 8 (7 to 14$) \%$ for EVLWi (Figure 1) and the precision for CI was $\geq 10 \%$ in 33 patients.

The LSC (for one single measurement) was 20 (14 to 29)\% for CI, 20 (14 to 34)\% for GEDVi and 20 (16 to $33) \%$ for EVLWi. If two boluses were used for TPTD, the LSC was reduced to 14 (10 to 21 )\% for CI, 14 (10 to 24)\% for GEDVi and 14 (11 to 23 )\% for EVLWi (Figure $2)$. If three boluses were used for TPTD, the LSC was 12 (8 to 17)\% for CI, 12 (8 to 19)\% for GEDVi and 12 (9 to 19$) \%$ for EVLWi (Figure 2).

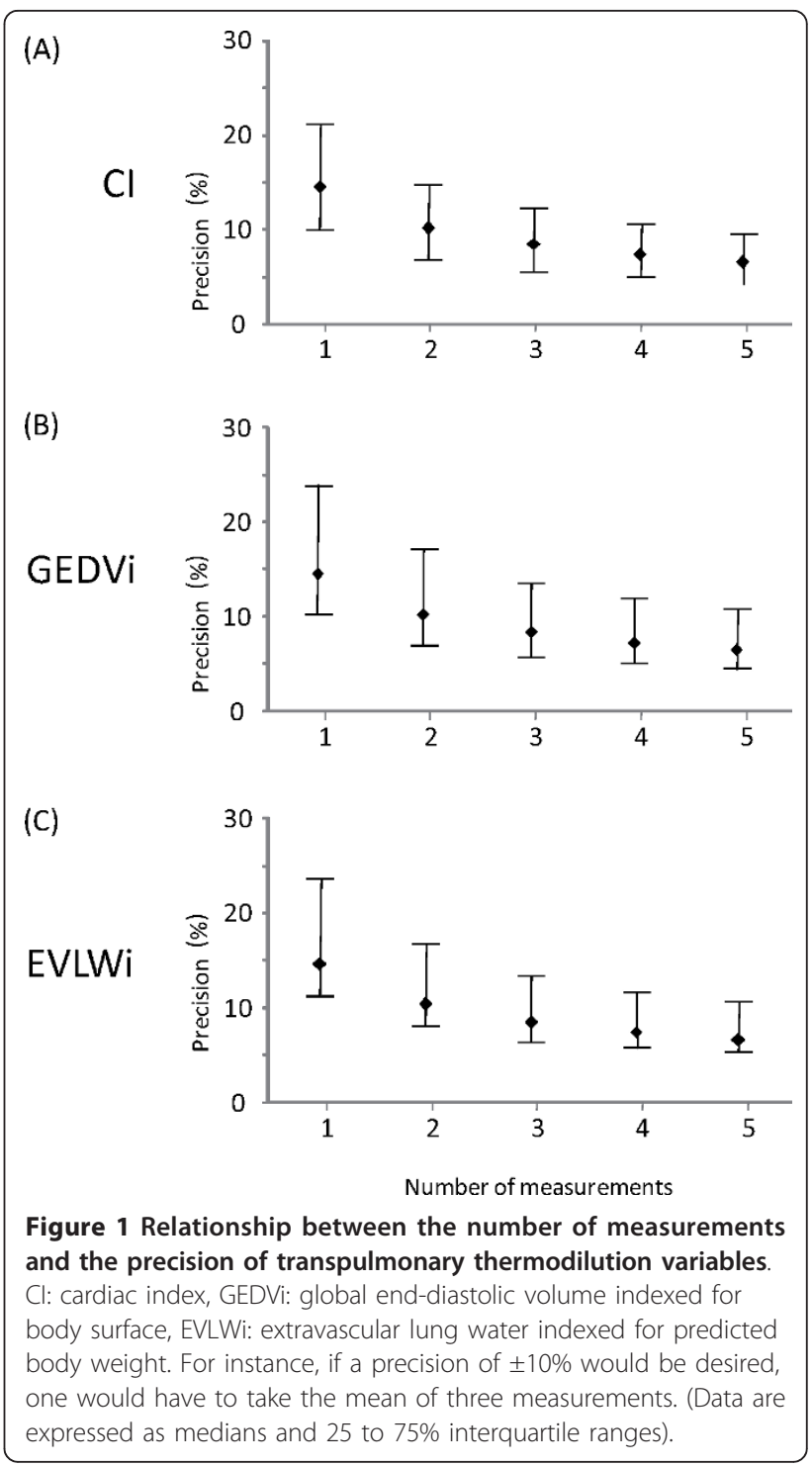

Factors influencing the precision of the transpulmonary measurements

Excluding the eight patients under continuous venovenous hemofiltration did not significantly change $\mathrm{CV}$, neither for CI (8 (6 to 12$)$ vs. (8 (6 to 12$)$ for three measurements) nor for GEDVi (8 (5 to 13$)$ vs. 8 (5 to 13) for three measurements) and EVLWi (8 (6 to 14 ) vs. 8 (6 to 14 ) for three measurements). Excluding the 23 patients with spontaneous breathing activity did not significantly change $\mathrm{CV}$, neither for CI (8 (5 to $12)$ vs. (8 (6 to 12$)$ for three measurements) nor for GEDVi ( 8 (5 to 13 ) vs. 8 (5 to 13 ) for three measurements) and EVLWi (8 (6 to 13$)$ vs. 8 (6 to 14 ) for three measurements). There was no significant correlation between the dose of norepinephrine and the precision of CItd $(P=0.06)$, GEDVi $(P=0.10)$ and EVLWi $(P=0.91)$. 


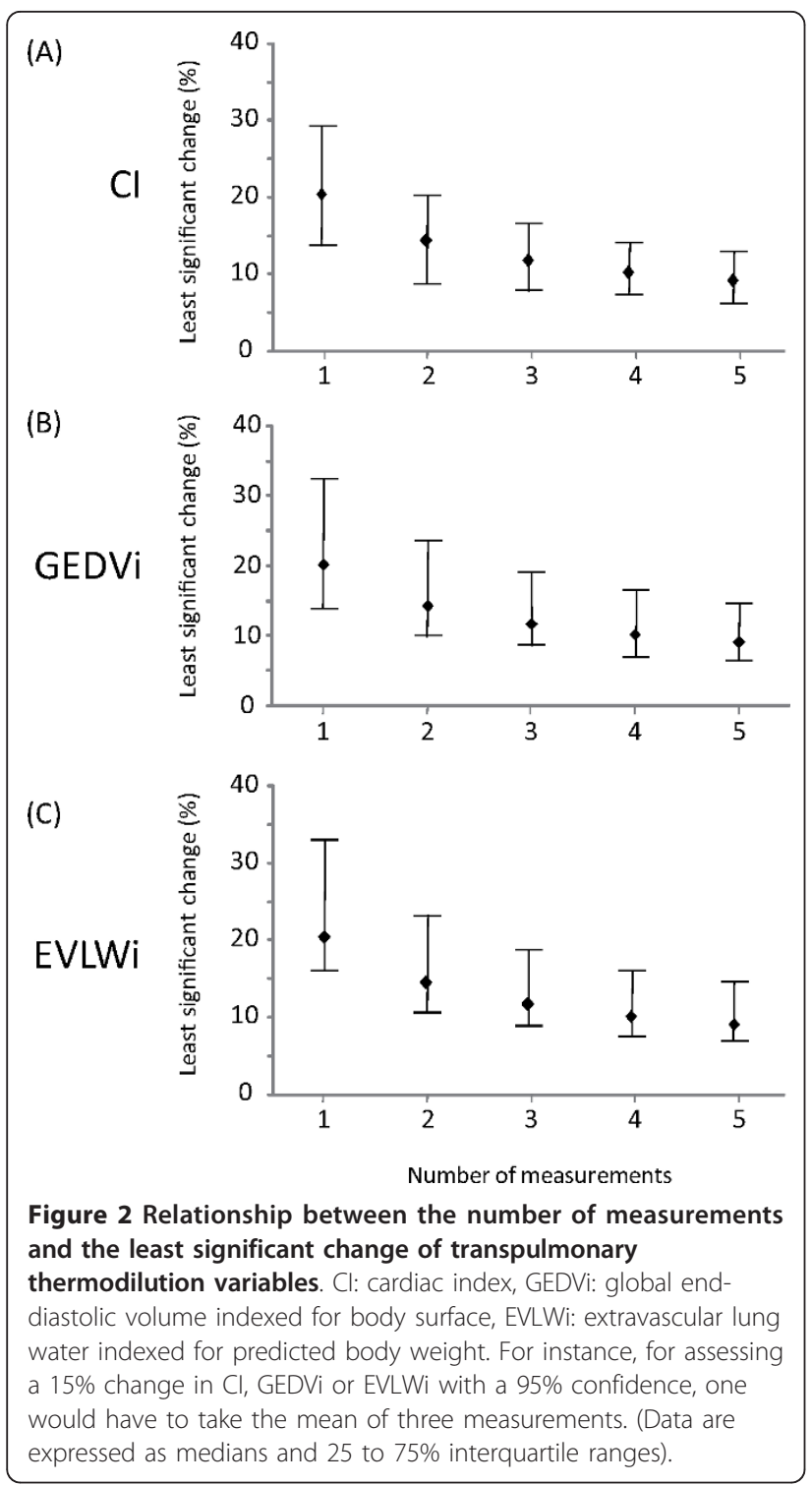

\section{Discussion}

This study shows that three thermodilution measurements are required for estimating CI, GEDVi and EVLWi through TPTD with an acceptable level of precision. If three thermodilution measurements are averaged, the technique allows detecting changes in CI, GEDVi and EVLWi of more than 15\% with an acceptable confidence.

There have been a number of studies reporting a good agreement between the measurement of CI by TPTD and by bolus pulmonary artery thermodilution [10-16] or by the Fick method $[17,18]$. By showing bias and limits of agreement of the TPTD CI compared to the reference $\mathrm{CI}$, these previous studies investigated the technique accuracy [1], that is, its ability to give a value of $\mathrm{CI}$ that is close to the reference value [9].
Nevertheless, validation of a technique monitoring CI should not only be based upon accuracy. Another key criterion to consider is precision, that is, the ability of the technique to provide values of CI that are close to each other [8]. Indeed, precision is a very important criterion for at least two reasons. First, it determines the least change that can be trusted with confidence as being significant in clinical practice. This is especially important for techniques measuring CI [19], since one is much more interested in variations of $\mathrm{CI}$ values over time than to a given CI value. Second, since precision increases with the number of measurements, it conditions the minimal number of measurements that must be replicated in clinical practice.

Our result concerning the precision of the TPTD measurement of $\mathrm{CI}$ is in accordance with two previous studies $[20,21]$ but in discrepancy with another one [2]. In particular, we found that averaging two measurements only might be insufficient for reaching an acceptable precision and that three thermodilution measurements are actually needed. However, the latter study [2] included a much more limited number of patients than our study. Interestingly, the precision of CI measurement we found for TPTD was similar to the precision reported by Cecconi et al. for another transpulmonary dilution device, the LiDCO system [22]. As the PiCCO device, this technique uses transpulmonary dilution but it uses lithium rather than cold saline as a diluted indicator. The similarity of precision between the two techniques suggests that their precision is more influenced by the transpulmonary dilution technique itself than the nature of the indicator.

We observed that, provided that three thermodilution measurements were averaged, the precision of the TPTD measurement of CI was within the $10 \%$ limit that is usually admitted as being desirable [8]. Comparison with the precision of the bolus pulmonary artery thermodilution is somewhat difficult, since the latter was evaluated by only a few studies. In a 20 -year-old study, Stetz et al. [23] found that precision of pulmonary artery catheter was similar to that we report with TPTD. More recently, Nilsson et al. reported a precision as low as $6 \%$ when averaging only three pulmonary artery thermodilutions [24]. If confirmed, these results would suggest that pulmonary artery thermodilution is more precise than TPTD.

The precision was almost similar for CI, GEDVi and EVLWi. This is not surprising since their measurement by TPTD share some common components. We could not analyze some constituents on which the measurement of CI, GEDVi and EVLWi is based, such as the mean transit time and down slope time of the thermodilution curve, what must be considered as a limitation of our study. Importantly, we found that the precision of 
TPTD measurements was not different when patients with cardiac arrhythmias, continuous veno-venous hemofiltration or spontaneous breathing were excluded from analysis. The absence of significant correlation between the dose of norepinephrine and the precision of CI, GEDVi and EVLWi suggests that vasopressors also do not influence the precision of TPTD measurements.

The good precision of EVLWi and GEDVi measurements is important as an increasing number of studies have proposed to consider EVLW as a prognostic factor $[4,5,25]$ or as a criterion of judgement for therapy [6] in acute respiratory distress syndrome, even though concerns have been raised concerning its reliability in this condition [26]. The results of the present study might have some important implications. The first ones are for daily clinical practice. By showing that injecting three cold boluses is sufficient for obtaining an acceptable precision of the technique, the study supports the manufacturer's guidelines of averaging three thermodilution measurements [7], a recommendation that, until now, was not based upon published data. If one considers that a precision of $8 \%$ is sufficient for CI, GEDVi and EVLWi, what is highly reasonable [27], repeating more than three boluses is useless. This might be important when considering that repeating cold injections is time consuming and that thermodilution must be frequently repeated in case of hemodynamic instability [28]. The second implication of the results is for clinical research purposes. For instance, it indicates that if three thermodilution measurements are averaged, a change in $\mathrm{CI}$, GEDVi or EVLWi of $15 \%$ or more can be considered as the cut-off defining a positive response to a therapeutic intervention $[21,29,30]$.

We acknowledge some limitations to our study. First, we did not exclude any measurement from analysis, while less skilled operators should do it when obtaining less reliable thermodilution curves. Second, the measurements were performed by only one skilled operator, precluding the assessment of inter-observer variability. Third, we did not investigate whether injecting more than $15 \mathrm{~mL}$ for performing each bolus could increase the precision of the technique. Fourth, the body temperature, CI, GEDVi and EVLWi values were within the normal range, such that the precision of TPTD for extreme values of these variables remains to be determined. In addition, we did not include patients with slow atrial fibrillation, which may affect the precision of TPTD measurements. Also, ideally, the measurements should have consisted of a series of five boluses compared to another series of five boluses for which one to five are randomly selected. Finally the precision of TPTD when using a humeral arterial catheter remains to be determined.

\section{Conclusions}

We found that three thermodilution measurements are needed for estimating CI, GEDVi and EVLWi with TPTD. If three thermodilutions measurements were averaged, this allowed detecting a $12 \%$ change in CI, GEDVi and EVLWi with a 95\% certainty. In addition to the accuracy of the technique, which has been already reported, these results may reinforce the level of evidence that TPTD is a reliable technique for monitoring critically ill patients.

\section{Key messages}

- Three thermodilution measurements are needed for estimating cardiac index, global end-diastolic volume and extravascular lung water with transpulmonary thermodilution

- If three thermodilution measurements are averaged, this allows detecting a $12 \%$ change in estimating cardiac index, global end-diastolic volume and extravascular lung water with a $95 \%$ certainty

\section{Abbreviations}

Cl: cardiac index; EVLWi: extravascular lung water indexed for predicted body weight; GEDVi: global end-diastolic volume indexed for body surface; SAPS: simplified acute physiologic score; TPTD: transpulmonary thermodilution.

\section{Author details}

${ }^{1}$ AP-HP, Hôpitaux Universitaires Paris-Sud, service de réanimation médicale, Le Kremlin-Bicêtre, F-94270 France. ' Univ Paris-Sud, Faculté de médecine Paris-Sud, EA 4046, Le Kremlin-Bicêtre, F-94270 France.

\section{Authors' contributions}

XM conceived the study, performed analysis and interpretation of the data, and drafted the manuscript. RP performed the collection of data, contributed to analysis and interpretation of the data and helped draft the manuscript. MK performed the collection of data, contributed to analysis and interpretation of the data, and helped draft the manuscript. MJ contributed to the collection of data, CR participated in the design of the study, contributed to analysis and interpretation of the data and helped draft the manuscript. J-LT conceived the study, participated in its design, contributed to analysis and interpretation of the data and helped draft the manuscript. All authors read and approved the final manuscript.

\section{Competing interests}

Profs. Jean-Louis Teboul and Xavier Monnet are members of the Medical Advisory Board of Pulsion Medical Systems. As consultants for this company, they received honoraria. The company did not finance the manuscript. The company was not involved in any part of the conception or performance of the study. The other authors declare that they have no conflict of interest.

Received: 10 March 2011 Revised: 30 May 2011

Accepted: 23 August 2011 Published: 27 August 2011

\section{References}

1. Reuter DA, Huang C, Edrich T, Shernan SK, Eltzschig HK: Cardiac output monitoring using indicator-dilution techniques: basics, limits, and perspectives. Anesth Analg 2010, 110:799-811.

2. Gondos T, Marjanek Z, Kisvarga Z, Halasz G: Precision of transpulmonary thermodilution: how many measurements are necessary? Eur J Anaesthesiol 2009, 26:508-512.

3. Sakka SG, Ruhl CC, Pfeiffer UJ, Beale R, McLuckie A, Reinhart K, MeierHellmann A: Assessment of cardiac preload and extravascular lung water 
by single transpulmonary thermodilution. Intensive Care Med 2000, 26:180-187.

4. Craig TR, Duffy MJ, Shyamsundar M, McDowell C, McLaughlin B, Elborn JS, McAuley DF: Extravascular lung water indexed to predicted body weight is a novel predictor of intensive care unit mortality in patients with acute lung injury. Crit Care Med 38:114-120.

5. Martin GS, Eaton S, Mealer M, Moss M: Extravascular lung water in patients with severe sepsis: a prospective cohort study. Crit Care 2005, 9: R74-82.

6. Perkins GD, McAuley DF, Thickett DR, Gao F: The beta-agonist lung injury trial (BALTI): a randomized placebo-controlled clinical trial. Am J Respir Crit Care Med 2006, 173:281-287.

7. Training documents for advanced hemodynamic monitoring. [http:// www.pulsion.com]

8. Squara P, Cecconi M, Rhodes A, Singer M, Chiche JD: Tracking changes in cardiac output: methodological considerations for the validation of monitoring devices. Intensive Care Med 2009, 35:1801-1808.

9. Cecconi M, Rhodes A, Poloniecki J, Della Rocca G, Grounds RM: Bench-tobedside review: the importance of the precision of the reference technique in method comparison studies-with specific reference to the measurement of cardiac output. Crit Care 2009, 13:201.

10. Della Rocca G, Costa MG, Chiarandini P, Bertossi G, Lugano M, Pompei L, Coccia C, Sainz-Barriga M, Pietropaoli P: Arterial pulse cardiac output agreement with thermodilution in patients in hyperdynamic conditions. J Cardiothorac Vasc Anesth 2008, 22:681-687.

11. Segal E, Katzenelson R, Berkenstadt H, Perel A: Transpulmonary thermodilution cardiac output measurement using the axillary artery in critically ill patients. J Clin Anesth 2002, 14:210-213.

12. Friesecke $S$, Heinrich $A$, Abel P, Felix SB: Comparison of pulmonary artery and aortic transpulmonary thermodilution for monitoring of cardiac output in patients with severe heart failure: validation of a novel method. Crit Care Med 2009, 37:119-123.

13. Zollner C, Polasek J, Kilger E, Pichler B, Jaenicke U, Briegel J, Vetter HO, Haller M: Evaluation of a new continuous thermodilution cardiac output monitor in cardiac surgical patients: a prospective criterion standard study. Crit Care Med 1999, 27:293-298.

14. Wiesenack C, Prasser C, Keyl C, Rodig G: Assessment of intrathoracic blood volume as an indicator of cardiac preload: single transpulmonary thermodilution technique versus assessment of pressure preload parameters derived from a pulmonary artery catheter. $J$ Cardiothorac Vasc Anesth 2001, 15:584-588.

15. McLuckie A, Murdoch IA, Marsh MJ, Anderson D: A comparison of pulmonary and femoral artery thermodilution cardiac indices in paediatric intensive care patients. Acta Paediatr 1996, 85:336-338.

16. Holm C, Melcer B, Horbrand F, Henckel von Donnersmarck G, Muhlbauer W: Arterial thermodilution: an alternative to pulmonary artery catheter for cardiac output assessment in burn patients. Burns 2001, 27:161-166.

17. Pauli C, Fakler U, Genz T, Hennig M, Lorenz HP, Hess J: Cardiac output determination in children: equivalence of the transpulmonary thermodilution method to the direct Fick principle. Intensive Care Med 2002, 28:947-952.

18. Tibby SM, Hatherill M, Marsh MJ, Morrison G, Anderson D, Murdoch IA: Clinical validation of cardiac output measurements using femoral artery thermodilution with direct Fick in ventilated children and infants. Intensive Care Med 1997, 23:987-991.

19. Critchley LA, Lee A, Ho AM: A critical review of the ability of continuous cardiac output monitors to measure trends in cardiac output. Anesth Analg 2010, 111:1180-1192.

20. Godje O, Thiel C, Lamm P, Reichenspurner H, Schmitz C, Schutz A, Reichart B: Less invasive, continuous hemodynamic monitoring during minimally invasive coronary surgery. Ann Thorac Surg 1999, 68:1532-1536.

21. Monnet X, Anguel N, Naudin B, Jabot J, Richard C, Teboul JL: Arterial pressure-based cardiac output in septic patients: different accuracy of pulse contour and uncalibrated pressure waveform devices. Crit Care 2010, 14:R109.

22. Cecconi M, Dawson D, Grounds RM, Rhodes A: Lithium dilution cardiac output measurement in the critically ill patient: determination of precision of the technique. Intensive Care Med 2009, 35:498-504.

23. Stetz CW, Miller RG, Kelly GE, Raffin TA: Reliability of the thermodilution method in the determination of cardiac output in clinical practice. Am Rev Respir Dis 1982, 126:1001-1004.
24. Nilsson LB, Nilsson JC, Skovgaard LT, Berthelsen PG: Thermodilution cardiac output-are three injections enough? Acta Anaesthesiol Scand 2004 48:1322-1327

25. Phillips CR, Chesnutt MS, Smith SM: Extravascular lung water in sepsisassociated acute respiratory distress syndrome: indexing with predicted body weight improves correlation with severity of illness and survival. Crit Care Med 2008, 36:69-73.

26. Groeneveld $A B$, Verheij J: Extravascular lung water to blood volume ratios as measures of permeability in sepsis-induced ALI/ARDS. Intensive Care Med 2006, 32:1315-1321.

27. Squara P: Bioreactance: A new method for non-invasive Cardiac Output monitoring. In Yearbook of Intensive Care and Emergency Medicine. Edited by: Vincent JL. Berlin, Heidelberg: Springer; 2008:619-630.

28. Hamzaoui O, Monnet X, Richard C, Osman D, Chemla D, Teboul JL: Effects of changes in vascular tone on the agreement between pulse contour and transpulmonary thermodilution cardiac output measurements within an up to 6-hour calibration-free period. Crit Care Med 2008, 36:434-440.

29. Jabot J, Teboul JL, Richard C, Monnet X: Passive leg raising for predicting fluid responsiveness: importance of the postural change. Intensive Care Med 2009, 35:85-90.

30. Monnet X, Osman D, Ridel C, Lamia B, Richard C, Teboul JL: Predicting volume responsiveness by using the end-expiratory occlusion in mechanically ventilated intensive care unit patients. Crit Care Med 2009, 37:951-956.

doi:10.1186/cc10421

Cite this article as: Monnet et al:: Precision of the transpulmonary thermodilution measurements. Critical Care 2011 15:R204.

\section{Submit your next manuscript to BioMed Central and take full advantage of:}

- Convenient online submission

- Thorough peer review

- No space constraints or color figure charges

- Immediate publication on acceptance

- Inclusion in PubMed, CAS, Scopus and Google Scholar

- Research which is freely available for redistribution

Submit your manuscript at www.biomedcentral.com/submit
Ciomed Central 